\title{
PERSISTENCIA Y CAMBIO EN LA CATALUÑa DE LA RESTAURACIÓN
}

\author{
BORJA DE RIQUER
}

\section{LA SOCIEDAD CATALANA EN LA RESTAURACIÓN}

Durante los 48 años del régimen de la Restauración las diferencias de carácter económico, social, cultural y político existentes entre Catal:iña y el resto de España se acrecentaron de forma notable. Cataluña pasó estos años por un acelerado proceso de modernización provocado por diversos factores entre los cuales destacan:

- un rápido crecimiento de la tasa de urbanización de la población y el inicio del movimiento migratorio hacia Cataluña.

- un importante proceso de diversificación económica y de nuevo impulso industrializador.

- la decadencia y despoblación de las zonas agrarias más atrasadas del interior del país.

Estos cambios socio-económicos irán acompañados de un acusado proceso de auto-organización asociativa de los diversos sectores sociales catalanes con lo que se irá configurando una «sociedad civil», principalmente en las ciudades, que desempeñará un decisivo papel en la sensibilización y movilización civico-política.

$Y$ todo esto, evidentemente, en un marco socio-laboral cada vez más conflictivo: en la Cataluña urbana la lucha de clases será mucho más acentuada, mucho más abierta y patente y mucho más consciente que en el resto de España.

Durante el casi medio siglo de la Restauración se producirá, como hemos indicado, una importante redistribución interna de la población catalana; el creciente éxodo rural y la acentuada concentración urbana irán pre-figurando dos Cataluñas: la más poblada y dinámica del litoral y pre-litoral y cada vez más despoblada y regresiva del interior central y occidental.

El rápido proceso de concentración de la población en grandes ciudades, y sobre todo en Barcelona, puede apreciarse con los siguientes porcentajes de lo que representaba Barcelona y las ciudades de más de 10.000 habitantes sobre el total de la població catalana: 
$\%$ de la población en ciudades sobre el total de Cataluña

\begin{tabular}{lllll}
\hline & 1857 & 1877 & 1900 & 1920 \\
\cline { 2 - 5 } Barcelona & $12 \%$ & $17 \%$ & $27 \%$ & $31 \%$ \\
Total más de 10.000 hab. & $28 \%$ & $33 \%$ & $41 \%$ & $47 \%$ \\
\hline
\end{tabular}

La capacidad de absorción de población de Barcelona, que en 1920 superaba los 700.000 habitantes, y las mayores ciudades catalanas era sin duda una clara muestra de la gran expansión de la industria y los servicios estos años.

Pero este proceso se había realizado hasta bien entrado el siglo XX a partir de la propia emigración interna catalana. Será después de 1910 cuando la llegada de gente procedente de fuera de Cataluña empezó a ser impúrtante. Así, si en 1904 sólo el 4\% de los residentes en Cataluña habían nacido fuera de ella, en 1920 el porcentaje ya llegaba al 14\%; durante la década 1910-1920 llegaron unas 250.000 personas procedentes fundamentalmente de Aragón, País Valenciano y Castilla.

El crecimiento vegetativo catalán era relativamente bajo como se puede deducir viendo que hasta 1910 la población catalana no se había incrementado con relación a la española: en 1877 Cataluña representaba el 10,5\% del total y en 1910 el porcentaje era el mismo. La emigración hará que en 1920 los residentes en Cataluña fueran ya 2.344 .719 , el $11 \%$ de la población total española.

Cataluña era, como ha dicho Jordi Nadal, «la fábrica de España», ya que en 1900 concentraba casi el $40 \%$ de toda la producción industrial española. Sin embargo durante los primeros años de la Restauración la situación económica catalana era crítica: la excesiva especialización en el textil (que en 1880 representaba el $98 \%$ de la producción industrial catalana) significaba depender de un sector en decadencia que tenía una tasa de crecimiento muy moderada dada la reducida demanda del mercado español.

Pero este estancamiento se superó a principios de siglo como resultado de un importante proceso de diversificación industrial (desarrollo de industrias de construcciones mecánicas, metalúrgia ligera, química y cemento) y de la creciente utilización de la energía hidroeléctrica. Si en 1913 menos de un $10 \%$ de la energía consumida por la industria catalana era de procedencia hidroeléctrica, en 1920 se había llegado al 70\%; la sustitución energética había sido rapidisima.

Además el propio proceso de urbanización de la población hacía que la concentración de recursos humanos se convirtiera en un estímulo para el crecimiento de la industria y de los servicios. 
Los efectos indirectos provocados por la centralización de las actividades industriales, comerciales y de servicios fueron notables así como la dinamización provocada por las grandes inversiones inmobiliarias e en el ensanche barcelonés.

De este modo el área industrial barcelonesa en los años 1910-1920 tenía incluso capacidad de atracción de inversiones extranjeras dada la propia infraestructura de servicios de la zona: la provincia de Barcelona era la que tenía más kilómetros de ferrocarril de toda España y el consumo de electricidad per cápita era en Cataluña el triple de la media española.

El carácter espectacular del crecimiento económico catalán de las primeras décadas del siglo queda reflejado en los cambios producidos en la distribución de la población activa, y aún más si se compara con la española:

$\%$ de la población activa por sectores

\begin{tabular}{|c|c|c|c|c|c|c|c|}
\hline \multirow[b]{3}{*}{ Agricul. } & \multicolumn{3}{|c|}{ Cataluña } & \multicolumn{4}{|c|}{ España } \\
\hline & 1900 & 1920 & & 1900 & 1920 & & \\
\hline & $52 \%$ & $33 \%$ & $=-19$ & $66 \%$ & $57 \%$ & $=$ & -9 \\
\hline Industr. & $27 \%$ & $41 \%$ & $=+14$ & $15 \%$ & $21 \%$ & $=$ & +9 \\
\hline Servici. & $19 \%$ & $24 \%$ & $=+5$ & $17 \%$ & $20 \%$ & $=$ & +3 \\
\hline
\end{tabular}

Como se ve las diferencias entre Cataluña y el conjunto español se habian incrementado notablemente en estos 20 años.

La Cataluña de 1920 erà ya un país fundamentalmente industrial que tenía un sector servicios creciente, a semejanza de buena parte de las zonas más desarrolladas de Europa occidental, mientras que el conjunto español aún no había salido del subdesarrollo agrario. Cataluña con sólo significar el $11 \%$ de la población concentraba el $30 \%$ del mercado español.

La agricultura catalana tuvo grandes dificultades para adaptarse a las nuevas necesidades del mercado y abordar el reto de la productividad. En 1900 el valor de la producción agraria era cuatro veces inferior al de la industrial, cosa que significaba que la productividad del campesino era casi 8 veces inferior a la del obrero industrial. Sin embargo, algunas comarcas lograron superar las dificultades y desarrollaron una agricultura competitiva gracias a la especialización, al sistemático uso de abonos y a la introducción de la mecanización.

Una sociedad como la catalana en pleno proceso de modernización de sus estructuras económicas lógicamente también tenía que sufrir importantes cambios en el terreno cívico y cultural. La tradición asociativa de carácter pro- 
fesional, económico, cultural y recreativo se reforzó notablemente; una importante red de ateneos populares, casals y centros de todo tipo se fueron creando por toda Cataluña como resultado de las aspiraciones populares al acceso a la cultura y, en buena medida, como alternativa al ineficaz, mediatizado e insuficiente sistema escolar existente.

También la creciente sensibilización de carácter catalanista se patentizará con la proliferación de publicaciones, asociaciones, actos y campañas reivindicativas que cada vez lograban movilizar a más amplios sectores sociales. Esta efervescencia catalanista creará el substrato que permitirá el arraigo del projecto político de la Lliga Regionalista a principios del siglo XX. Y dentro de este movimiento debe destacarse el papel dirigente desempeñado por una nueva generación de intelectuales claramente comprometidos con el resurgir cultural y político de Cataluña.

\section{ETAPAS DE LA EVOLUCIÓN POLITICA CATALANA}

\subsection{Los inicios: $1875-1890$}

Durante el sexenio democrático (1868-1874) el panorama político catalán ya había sido notablemente diferente y extremadamente complejo: en Cataluña el bloque gubernamental liberal-monárquico no logró imponerse ni política ni electoralmente ya que el republicanismo federal triunfó de forma generalizada tanto en las elecciones generales como en las provinciales y municipales por lo que los federales gobernaron en los principales ayuntamientos y en las diputaciones provinciales. A esto debe añadirse que el carlismo controlará a partir de 1872 casi un $25 \%$ del territorio catalán y que actuará militarmente y de forma sistemática en otro $25 \%$.

Así, con una montaña dominada por los carlistas y con unas clases populares urbanas cada vez más radicalizadas y en plena «rebelión social» (creciente difusión del socialismo internacionalista), era lógico que la alta burguesía catalana adoptase actitudes claramente ultraconservadoras y que se apresurase a conspirar para liquidar aquella "pesadilla» de régimen democrático.

Por todo esto lo que más caracterizará los primeros años de la Restauración en Cataluña será la actitud de defensa social de la alta burguesía que constantemente exigirá la creación de un estado fuerte que impida a toda costa la difusión de las ideologías revolucionarias y la reorganización de los «subversivos» republicanos y sindicalistas. Para la clase dominante catalana la Restauración no era sólo el restablecimiento dinástico sino, sobre todo, el restablecimiento de la disciplina social y de los valores conservadores perdidos durante la «traumática» experiencia del sexenio. 
Así, hasta 1890 habrá un evidente consensus entre los sectores dominantes catalanes para cerrar filas ante los posibles peligros del insurreccionarismo republicano o de un nuevo brote carlista. El apoyo al sistema político será explícito pese a las frecuentes denuncias sobre las «ambigüedades ideológicas» del canovismo o los excesivos «vicios de procedimiento» de los gobiernos dinásticos.

Esta etapa, por tanto, se caracterizará por la escasa movilización políticoelectoral y por el predominio del tradicional liberalismo oligárquico que hacía funcionar el turno en Cataluña sin excesivos problemas. El enfrentamiento entre conservadores y liberales (estos contarán casi siempre con el apoyo posibilista) marcará la vida electoral en la que serán frecuentes todo tipo de alteraciones fraudulentas del sufragio y los conflictos a escala municipal. El turismo sólo será contestado a nivel local por sectores de las «fuerzas vivas» que no se sentian representados por los cuneros de turno.

La represión del obrerismo más radical y la política discriminatoria con republicanos y carlistas permitirá excluir del juego político a las fuerzas consideradas como más peligrosas para el sistema.

Sin embargo durante los años 80 las movilizaciones de carácter proteccionista organizadas por las asociaciones económicas conseguirán un amplio apoyo social y pondrán a la clase política dinástica de Cataluña en el dilema de participar, o incluso encabezar, la protesta antigubernamental o perder gran parte de su propia representatividad. En los partidos dinásticos de Cataluña, sobre todo en el conservador, empezarán a producirse tensiones como consecuencia de su carácter sucursalista y su prestigio político comenzará a erosionarse.

Por otra parte la crisis agraria de los 80 no sólo patentizó la irreversible decadencia del mundo rural catalán y su clara subordinación a la sociedad urbana sino que también generará una acusada conflictividad en las comarcas vinícolas en las que se producirán importantes movilizaciones campesinas que tendrán una repercusión político-electoral en la década siguiente.

\subsection{Del sufragio universal a la crisis colonial: $1891-1900$}

La última década del siglo será una etapa de transición evidente hacia una política de masas y de movilizaciones políticas, sindicales y culturales.

El republicanismo resurgirá con fuerza pese a sus profundas divisiones internas y la implantación del sufragio universal posibilitará su duro enfrentamiento con los dinásticos. Los republicanos lograrán éxitos en las elecciones generales, provinciales y municipales tanto en las grandes ciudades como en las comarcas de mayor conflictividad y movilización campesina (Penedés, 
Camp de Tarragona, Conca de Barberá, Vallés, Ampurdán, etc.) Debe recordarse que un tercio de los diputados a Cortes republicanos de los años 1891 y 1893 serán elegidos en Cataluña. De todas formas estos éxitos serán puntuales y estarán muy localizados en ciertos distritos por lo que con la regresión política de los años 1895-1900 el republicanismo catalán perderá buena parte de las posiciones logradas.

El obrerismo se reorganizará notablemente y protagonizará las primeras grandes movilizaciones reivindicativas de la Restauración (huelgas generales de 1890 y 1891). Pero los intentos por extender el socialismo marxista (PSOE) entre los obreros catalanes fracasarán como consecuencia de las estrechas relaciones que una parte del republicanismo mantenía con el sindicalismo más moderado y por el claro apoliticismo de los sectores más radicales (anarquistas). El estallido terrorista de los años 1893-1896 permitirá a las autoridades ejercer una desproporcionada y generalizada represión de toda la izquierda; no sólo los sectores pro anarquistas sino hasta el propio republicanismo así como el sindicalismo moderado, que era el más influyente y organizado, serán perseguidos y desmantelados. La utilización de ejército contra las movilizaciones obreras y campesinas y contra el terrorismo ácrata demostrará la reducida capacidad integradora del régimen liberal y la voluntad gubernamental de cortar por lo sano toda posible vinculación entre el republicanismo y el obrerismo más radical. De igual modo la dura represión de las actitudes contrarias a la guerra colonial reflejará la escasa aceptación de las discrepancias en cuestiones «de estado».

En el sistema de la Restauración el estado no moderaba las tensiones sociales sino que era claramente beligerante en favor de los intereses de las clases propietarias hecho que confirmará la opinión popular de que éste, el estado, era «su principal enemigo». Los gobiernos dinásticos, tanto los conservadores como los liberales, recurrirán frecuentemente estos años a medidas represivas de todo tipo y de este modo los años 90 serán en Cataluña una época extremadamente agitada y dura: entre noviembre de 1893 y marzo de 1901 la provincia de Barcelona estará 56 meses y medio con las garantías constitucionales suspendidas o en estado de guerra.

$Y$ estos sucesos coincidían con el desarrollo de un importante movimiento catalanista de carácter cívico-cultural que si bien no actuaba directamente en la vida política constituía también un nuevo factor de desestabilización y erosión del sistema de la Restauración, sistema que no se caracterizaba precisamente por ser flexible y tolerante ante las reivindicaciones de carácter regionalista por moderadas que fuesen.

El desastre colonial del 98 provocará en Cataluña una muy generalizada 
reacción de rechazo de los partidos dinásticos a los que se consideraba responsables directos del fracaso militar y político. Esta actitud de protesta tendrá como principales protagonistas a las asociaciones económicas y ciudadanas de Barcelona. El posterior fracaso del proyecto regeneracionista ofrecido por el gobierno Silvela-Polavieja en 1899 acentuará el desprestigio del sistema político entre las "clases neutras» barcelonesas que buscarán y encontrarán en el catalanismo una vía propia para encauzar sus aspiraciones de reforma y regeneración de la vida política española.

A las protestas ciudadanas catalanas, que alcanzarán su máxima cota con la huelga de contribuyentes de 1899 , responderán los gobiernos de nuevo con una política básicamente represiva: la provincia de Barcelona vivirá en estado de guerra desde 1899 a 1901, la prensa no adicta (catalanista, republicana y obrerista) será perseguida y algunos de los dirigentes más conocidos de la oposición serán encarcelados (Prat de la Riba) o se verán obligados a exiliarse. $Y$ de nuevo el ejército desempeñará un importante papel en esta operación de represión de toda la contestación al sistema.

En estas circunstancias no es de extrañar que se produjera una coincidencia política entre los más activos dirigentes de las asociaciones económicas y ciudadanas barcelonesas y el sector más pragmático del catalanismo (el grupo de Prat y "La Veu de Catalunya»). La victoria electoral de la candidatura formada por estos sectores en las elecciones generales de 1901 en la ciudad de Barcelona posibilitará la formación de una nueva fuerza política: La Lliga Regionalista. El triunfo de la Lliga sobre la candidatura de coalición dinástica reflejaba lo mucho que había cambiado la opinión pública barcelonesa en los decisivos y agitados años del final del siglo XIX. Los viejos partidos de notables poco tenian que hacer ante las aspiraciones y exigencias ciudadanas de participar activamente en la vida política.

\subsection{Catalanismo y republicanismo: $1901-1909$}

A partir de 1901 la situación política catalana estará condicionada por la emergencia del catalanismo activo (la Lliga) como una fuerza con capacidad de convertirse en el protagonista fundamental y el eje central de la vida barcelonesa: todas las otras formaciones políticas se verán obligadas a definirse y actuar en función de lo que representaba y hacia la Lliga.

La Lliga Regionalista contará con el apoyo fiel de amplios sectores de las clases altas y medias y se configurará como un moderno partido de cuadros y de dirigentes profesionalizados. A medida que gane influencia fuera de Barcelona la Lliga se convertirá en el partido de las clases conservadoras urbanas y rurales de buena parte de Cataluña. 
El proyecto catalanista de la Lliga estaba basado tanto en la táctica de acceder al control de todos los órganos de poder existentes (ayuntamientos y diputaciones, fundamentalmente) como en la exigencia de un gobierno autonómico catalán, aspiración contemplada como un elemento básico para la necesaria reforma política de todo el sistema de la Restauración.

La fulgurante aparición de la Lliga en la escena política será recibida con notable hostilidad por conservadores y liberales que no querían, ni podían, aceptar la existencia de sectores burgueses que se escindieran del dinastismo y que sólo veían en el catalanismo un inminente "peligro separatista».

Pero junto a la Lliga también en Barcelona ese mismo año 1901 había resurgido con fuerza el republicanismo bajo el liderazgo de Alejandro Lerroux. El lerrouxismo significará un nuevo tipo de partido popular de masas, contará con miles de afiliados, recurrirá constantemente a la movilización en las calles y creará una amplia red de centros político-asistenciales en los que atender a su numerosa clientela obrera. El éxito de esta nueva política republicana se verá reforzado por la decepción producida entre los sectores obreros barceloneses por los sucesivos fracasos de las propuestas de «revolución inmediata» formuladas por los ácratas (huelga general de 1902).

Así, Lliga y lerrouxismo se disputarán el dominio político de Barcelona protagonizando un enfrentamiento tan duro como peculiar: la nueva derecha representada por la Lliga pretenderá erigirse en la única defensora de los intereses de Cataluña; el lerrouxismo, por su parte, ambicionará monopolizar la representación de las clases populares barcelonesas.

Estas aspiraciones hegemónicas de una y otra fuerza dificultarán el desarrollo de una vía intermedia, la del republicanismo nacionalista. Los diferentes intentos de cohesionar una alternativa a ambas formaciones políticas acabaran siempre en un rotundo fracaso. El dilema estaba entre optar o por la republicanización del catalanismo, es decir ser la alternativa de izquierdas a la Lliga, o por la catalanización del republicanismo, disputando a Lerroux la dirección de este movimiento. Los republicanos nacionalistas no acabaron de decidirse por ninguna de las dos políticas y buscaron estérilmente un espacio intermedio que aún no existía en la escena política catalana.

La batalla de Barcelona conducirá a la desaparición en esta ciudad del bipartidismo dinástico sin demasiadas resistencias y de forma rápida. Esta ruptura política no sólo se caracterizará por su continuidad (nunca más será elegido en Barcelona un diputado dinástico) sino también por que significará el paso a un sistema político-electoral de masas: creciente participación en elecciones (siempre superior al $40 \%$ ), campañas electorales agitadas y con gran asistencia a los mítines, creación de aparatos electorales en los partidos, efi- 
ciente control del sufragio y del censo, etc. Esta política de masas se fue imponiendo en Barcelona pese a los intentos de los diferentes gobiernos para evitar que se consolidara. Este hecho no es una prueba de que era posible la democratización del sistema de la Restauración "desde dentro», sino de todo lo contrario, significa que la democratización lo que provocaba era la crisis del liberalismo oligárquico, que era la misma esencia del sistema canovista.

La modernización de la práctica político-electoral se fue extendiendo progresivamente a otras ciudades pero fue la Solidaritat Catalana el principal factor de difusión de los nuevos modos políticos y de la acentuación de la crisis del caciquismo dinástico en el resto de Cataluña.

La Solidaritat Catalana se constituyó en 1906 como una evidente reacción patriótica a la creciente hostilidad anticatalanista que se apreciaba en los partidos dinásticos y, sobre todo, entre los militares. Por ello la Solidaritat tuvo el carácter de movimiento opuesto a todo lo que representaban los partidos dinásticos cosa que explica que hiciera de la lucha contra «el caciquismo gubernamental» uno de sus principales objetivos. El resultado fue la movilización política más importante de la historia catalana de la Restauración: manifestaciones masivas, centenares de mítines y una rotunda victoria electoral en las elecciones generales de 1907: con una participación de más del 60\% del electorado los solidarios obtuvieron 41 de los 44 escaños catalanes.

Pese a que esta espectacular derrota dinástica sería desigual en su continuidad evidentemente después de las elecciones de 1907 el voto en Cataluña tendió a ser mucho más representativo, la realización de campañas electorales se convirtió en una exigencia obligada y la proclamación de diputados sin lucha fue cada vez más rara: el número de actas conseguidas por el artículo 29 será en Cataluña a partir de entonces cinco veces inferior al de Galicia o Andalucía y una tercera parte de la del País Valenciano. También la corrupción será mucho menor como lo prueba el que el número de actas anuladas por el Tribunal Supremo entre 1910 y 1923 fuera en Cataluña muy inferior a las regiones españolas de similar población.

La heterogénea composición de la Solidaritat (sólo los dinásticos y lerrouxistas estaban al margen) y la política de Maura de acercamiento a la Lliga (proyecto de ley de administración local) acabaron por deshacer este movimiento en 1909.

\subsection{La hegemonía de la Lliga: 1910-1917}

La crisis de julio de 1909 (la llamada Semana Trágica de Barcelona) provocará una grave división de la sociedad catalana. La Lliga Regionalista sur- 
girá de ella reforzada como la única opción conservadora capaz de enfrentarse con éxito al radicalismo anticlerical y a la «rebelión» de las clases subalternas. Esta confirmación de su carácter derechista, clerical y de orden posibilitará un mejor entendimiento con los conservadores dinásticos españoles, especialmente con Maura y Dato.

Con notable pragmatismo la Lliga logrará ser el principal polo de atracción de toda la derecha catalana convirtiendo progresivamente en satélites de su política de defensa social a carlistas, ultracatólicos e incluso dinásticos.

La hegemonía de la Lliga se construirá con ese apoyo social conservador y se concretizará a partir del control de las diputaciones provinciales de Barcelona y Girona, del Ayuntamiento de Barcelona (desde 1915) y, sobre todo, de la Mancomunitat de Catalunya (a partir de 1914).

Con la constitución de esta confederación de las 4 diputaciones catalanas los hombres de la Lliga pudieron empezar a desarrollar su ambicioso programa político: dotar a Cataluña de una institución que pese a lo reducido de sus competencias pudiera servir para que ellos se ejercitasen como «hombres de gobierno» eficaces y así adquirir la experiencia, prestigio y fuerza suficientes para después presentarse como los nuevos dirigentes que necesitaba la política española.

Pero el paso previo era «reconstruir» Cataluña, nacionalizarla y homogenizarla ideológica y políticamente. De ahí el destacado papel que se otorgará a los intelectuales como creadores y transmisores del proyecto de la «nueva Cataluña» del siglo XX (el noucentisme). El compromiso político de buena parte de la intelectualidad catalana con el proyecto de la Lliga no sólo los convertirá en hombres de partido al servicio de una política sino también en profesionales de la administración catalana (Mancomunitat) y, por lo tanto, en asalariados del poder, creando así unas nuevas relaciones de subordinación y dependencia entre los intelectuales «orgánicos» y los políticos.

El control de la Mancomunitat permitirá a la Lliga extender su influencia política hacia las comarcas de la «Catalunya nova» (Lleida y Tarragona) donde aún no había logrado penetrar con fuerza e intentar desbancar a dinásticos y republicanos. La progresiva incorporación a la Lliga de líderes y caciques locales de las más variadas procedencias (dinásticos, carlistas e incluso republicanos) se producirá a medida que se imponía una dinámica política catalana, y no localista, que obligaba a resituarse o correr el riesgo de quedar marginado. La Lliga reconocerá y respetará los intereses locales de estos líderes con lo que su pragmatismo político llegará al extremo de defender actitudes democráticas en unos distritos y consolidar el poder caciquil en otros.

El republicanismo catalán no logró después de 1909 configurar una al- 
ternativa de izquierdas a la Lliga ni cuando los lerrouxistas y los nacionalistas formalizaron alianzas electorales. La voluntad de proyección estatal de Lerroux le obligará a moderar su discurso extremista y abandonar su orientación obrerista y anti-sistema. Pero este «transformismo» de los radicales tampoco posibilitará el éxito de los republicanos nacionalistas: el fracaso de esta opción radicaba en la persistencia de formas y actitudes aún propias de la vieja política decimonónica, como el hecho de pretender hacer una política de masas populista con un partido dirigido por intelectuales no dispuestos a profesionalizarse en la política y extremadamente reacios a toda orientación obrerista.

Así el republicanismo catalán pese a conservar una importante presencia en la vida política, y más aún a escala española ya que aportaba casi la mitad de los diputados a Cortes, no logró erigirse como una alternativa de izquierdas consistente a la hegemonía de la Lliga Regionalista. Los republicanos mantuvieron influencias de tipo local y comarcal pero se vieron obligados a ceder el control de Barcelona a la Lliga a partir de 1915.

Pero la constitución de la Mancomunitat se había convertido también en el catalizador de la crisis y fragmentación de los partidos dinásticos en toda España. La cuestión catalana, como puede apreciarse por los agitados debates parlamentarios de 1911 y 1912 , actuaba como elemento acelerador de las divisiones internas de unos grupos políticos ya bastante fragmentados por problemas más personales que ideológicos. Con ello el sistema político español entraba en una fase de creciente inestabilidad ya que cada vez sería más difícil crear mayorías parlamentarias sólidas.

Como es sabido la ofensiva encabezada por la Lliga en la primavera de 1917 para forzar la reforma del sistema político, aprovechándose de la división extrema de los dinásticos y de la debilidad del gobierno Dato, acabará con un espectacular cambio de táctica del catalanismo conservador. Ante el peligro de ser desbordada por la izquierda por republicanos, socialistas y sindicalistas la Lliga pactó con los dinásticos y aceptó formar parte del gobierno con ellos: así, de luchar por una radical reforma política del sistema la Lliga pasó a defender el "cambio desde dentro" ante el temor de desestabilizar la propia monarquía y poner en peligro el orden social conservador.

\subsection{Crisis social y crisis politica: $1917-1923$}

Entre 1917 y 1923 la Lliga Regionalista accederá al gobierno español en diversas ocasiones pero esta presencia no implicará cambios sustanciales en el funcionamiento del sistema político ni reforma alguna de importancia.

La Lliga se verá obligada a desempeñar un papel contradictorio: actuar 
de «partido de gobierno» con visión de estado en Madrid y mantener el discurso nacionalista en Barcelona. Y esto, en el fondo, sólo hizo que deteriorar su propia imagen política en Madrid y en Barcelona al tiempo que acentuaba la inestabilidad política del régimen.

Así, la campaña pro-estatuto de autonomía catalán de los años 1918-1919 provocó graves tensiones en casi todos los partidos políticos españoles ya que a las divergencias político-ideológicas existentes se sumaron las divisiones entre los reformistas pro-autonomistas y los centralistas obstinados.

La actitud del propio rey y de los sectores más inmovilistas de la clase política dinástica con la Lliga fue entonces más grosera que hábil: la creación palaciega de la Unión Monárquica Nacional, en 1919, fue un fallido y tardío intento de construir una derecha españolista en Cataluña frente a la «siempre sospechosa" política de la Lliga. Pero este proyecto no tenía ni unos líderes atractivos ni socialmente difería mucho del catalanismo conservador.

El surgimiento en Cataluña de un potentísimo movimiento obrero de orientación anarco-sindicalista (la CNT) que a partir de 1916 ejercerá una notable presión revindicativa será el elemento clave de la crisis social y política de estos años. La CNT no sólo conseguirá una clara hegemonía entre la clase trabajadora catalana (en 1919 tenía unos 400.000 cotizantes) si no que además protagonizará una ofensiva obrera de magnitudes hasta entonces desconocidas: entre 1916 y 1920 la zona industrial de Barcelona tendrá el índice de huelgas más alto de Europa occidental.

La dura respuesta patronal al desafío de la CNT (lock-out, listas negras, sindicalismo amarillo, pistolerismo blanco, etc.) conducirá a una espiral de violencia extremadamente dura: entre 1918 y 1923 caerán asesinados a tiros en Barcelona 49 patronos y encargados, 19 policías y 205 sindicalistas.

Todo este duro enfrentamiento social se dirimía al margen del juego político-electoral. El abstencionismo activo del anarco-sindicalismo y la incapacidad política de los republicanos para representar las aspiraciones obreras hizo que esta enorme presión social no se manifestara por los cauces legales con lo que la ya limitada representatividad del sistema no hizo más que acentuarse. Sin duda existía una clara relación entre la acentuación de la crisis social y el abstencionismo en la ciudad de Barcelona como queda reflejada en el hecho de que a partir de 1914 la participación electoral ya nunca alcance el $50 \%$ y que en ciertos momentos críticos, como en 1920 , sólo vote en la ciudad condal el $30 \%$ del censo. El abstencionismo consciente de buena parte de los obreros barceloneses también quedó patente en las elecciones de 1918 cuando la coalición de todas las izquierdas (republicanos y PSOE) no logró vencer a la Lliga en Barcelona: entonces sólo votó el $43 \%$ del censo. 
La Lliga Regionalista, presionada por su base social conservadora y por las organizaciones patronales, adoptó una política cada vez más defensiva frente al «peligro revolucionario» cosa que significó el aplazamiento sine die de sus proyectos reformistas y autonómicos. Como explica Cambó en sus «Memòries" había que salvar la sociedad amenazada, en ello les iba «la vida». Esta actitud, juzgada de claudicante por algunos sectores catalanistas, posibilitará el desarrollo de grupos nacionalistas radicales aunque ninguno de ellos tendrá una incidencia política y electoral destacable.

El republicanismo catalán en estas circunstancias críticas acelerará su descomposición y se dividirá entre los sectores más moderados, que acabarán siendo unos satélites más de la política de la Lliga, y los más izquierdistas, que pugnaran estérilmente por conseguir el voto cenetista.

Pero la propia crisis social y política estaba favoreciendo la creación entre las clases altas catalanas de un ambiente partidario a la adopción de medidas autoritarias para defender con mayor eficacia el amenazado orden social. Dirigentes de organizaciones patronales criticarán públicamente la acción gubernamental por considerarla vacilante y excesivamente escrupulosa con la legalidad. Es importante destacar el apoyo que estos sectores darán a la formación a partir de 1919 de una especie de «contra-poder militar» en Barcelona (generales M. Anido y Arlegui) cuya actuación cada vez más autónoma iba en claro detrimento de las propias atribuciones gubernamentales. Este "contra-poder" se fue consolidando a medida que ganaba apoyos burgueses y que la crisis del sistema parlamentario español propiciaba gobiernos débiles e inestables.

La crisis de 1917-1919 evidenció que el sistema no podía democratizarse desde dentro mediante el voto, porque la regla de oro del viejo sistema ideado por Cánovas era que el poder no dependía del voto sino los votos del poder, y eso no podía alterarse sin hundir todo el entramado político. Pero a partir de 1920, aproximadamente, la crisis catalana planteó una cuestión aún más grave: la guerra social se estaba dirimiendo cada vez más al margen, y por ello en contra, del propio sistema liberal.

Entre 1919 y 1923 puede afirmarse que la sociedad catalana estaba inmersa en el duro enfrentamiento entre la política cada vez más ultraconservadora de la Lliga, y de los sectores burgueses antidemocráticos que se estaban creando, y la ambición revolucionaria de la CNT, que amenazaba con destruir la sociedad de los propietarios. Ambos proyectos tendian progresivamente a buscar sus propios medios de acción y a desconocer las instituciones politicas del sistema liberal como cauces válidos para expresar y lograr sus aspiraciones. 
El divorcio entre un sistema político anquilosado que había sido construido para que no hubiesen movilizaciones ciudadanas y una sociedad como la catalana en plena efervescencia y confrontación no podía ser ya más evidente.

En 1923 Cataluña, «la Irlanda de España», estaba llevando al sistema de la Restauración a un callejón sin salida legal, ya que la crisis catalana se había convertido en un verdadero "cáncer» que aceleraba el fin de un sistema político incapaz de integrar a los nuevos sectores sociales movilizados.

Pero la crisis también evidenciaba la no vertebración política, social y cultural de España como una nación consolidada. En la sociedad catalana de estos años se estaban planteando una serie de exigencias políticas que los dirigentes dinásticos españoles no podian entender ni compartir, porque su resolución implicaba el fin de toda una forma de hacer política y un cambio demasiado profundo para el viejo sistema de la Restauración.

NOTA BIBLIOGRÁFICA

La bibliografía sobre Cataluña durante la Restauración no es escesivamente abundante, salvo en ciertas temáticas como catalanismo o historia económica, ni demasiado satisfactoria. La obra ya clásica de Jaume Vicens i Vives Industrials i Politics del segle XIX (Barcelona, Ed. VicensVives, 1958) pese a sus años, insuficiencias y a las numerosas aportaciones monográficas publicadas desde entonces, continúa siendo la «tesis interpretativa" básica y el principal punto de referencia.

La más destacable sintesis de historia catalana de esta época es sin duda el volumen VI de la Historia de Catalunya dirigida por Pierre Vilar titulado «De la Revolució de Setembre a la fi de la Guerra Civil, 1868-1939», que es obra de Josep Termes (Barcelona, Edicions 62, 1987).

La obra de diversos autores (J. Fontana, C. Marti, J. Nadal i Oller, P. Pascual, B. de Riquer, R. Solá, C. Sudriá y J. Termes), Catalunya i Espanya al segle XIX (Barcelona, Columna, 1987), contiene importantes aportaciones monográficas entre las que destacan, para la temática que nos interesa: "L'economia catalana en el marc de l'economia espanyola: Catalunya, la fàbrica d'Espanya (1833-1936)" de Jordi Nadal i Oller; «La vida política catalana (1856-1898)", de Borja de Riquer; y «Corrents de pensament i d'acció del moviment catalanista» de Josep Termes.

También debe citarse el dosier publicado en el número 85 de la revista L'Avenç (Barcelona, setiembre de 1985) titulado «La Restauració de 1875, una reacció conservadora», que incluye los siguientes artículos «Burgesos, polítics i cacis a la Catalunya de la Restauració» de Borja de Riquer, «El marginament del republicanisme y l'obrerisme» de Pere Gabriel, «Entre l'abisme i la realitat: estratégies del catolicisme catalá» de Josep M. Fradera y "L'economia catalana» de Xavier Tafunell.

Una excelente aportación sobre la crisis catalana de 1917-1923 puede encontrarse en los capítulos redactados por Enric Ucelay Da Cal en la História de Diputació de Barcelona (Barcelona, Diputació, 1987) titulados «La Diputació i la Mancomunitat: 1914-1923» y «La Diputació durant la Dictadura: 1923-1940». 